\title{
Análise do sistema de classificação por cor/ raça no Brasil ${ }^{1}$
}

\author{
Análisis del sistema de clasificación por color / raza en Brasil \\ Analysis of the color / race classification system in Brazil
}

\author{
Guilherme Nogueira de Souza ${ }^{2}$
}

\begin{abstract}
Resumo
O Brasil é o país com a maior população afrodescendente de toda América Latina. O processo de colonização portuguesa, ao introduzir o trabalho compulsório de nativos dos mais diferentes grupos sociais africanos e privilegiar a povoação e controle do território via intercurso sexual com nativos indígenas e escravos, deu origem a uma nação miscigenada e, ao mesmo tempo, marcada por uma ampla desigualdade social e econômica que assume perceptíveis traços raciais. O sistema de classificação de raça/ cor que se desenvolveu no Brasil está intimamente relacionado ao processo colonial. Nos dias atuais, pode-se dizer que há dois grandes sistemas de classificação étnico-racial no país: o oficial e o de uso cotidiano. O oficial está assentado em cinco categorias, quatro referentes à cor (branco, preto, pardo e amarelo) e uma referente à etnia (indígena). O sistema de uso cotidiano, mais flexível que o sistema oficial, varia segundo o tipo de interação interpessoal. Ambos os sistemas de classificação racial, no entanto, estão assentados nas características físicas dos sujeitos (com exceção da categoria oficial "indígena"), tendo a cor da pele como elemento fundamental no processo de classificação. No entanto, nos últimos 20 anos, a lenta e silenciosa ascensão socioeconômica de parcelas da população negra brasileira, o processo de discussão das desigualdades sócio-raciais, a emergência de diferentes políticas de combate à desigualdade social e a implantação de políticas compensatórias focadas na população negra tem gerado amplos debates públicos entre pesquisadores, gestores e militantes de movimentos sociais a respeito das categorias de classificação e seus usos. É neste contexto que o presente artigo discute o sistema de classificação racial, sua estruturação, transformações e usos cotidianos, focando na população negra brasileira.
\end{abstract}

Palavras-Chave: desigualdade; identidades sociais; racismo; relações raciais; sistema de classificação.

\section{Resumen}

Brasil es el país con la mayor población afrodescendiente de toda América Latina. El proceso de colonización, mediante la introducción de trabajo esclavo de diferentes colectivos sociales africanos y al favorecer el asentamiento y el control del territorio a través de las relaciones sexuales con los nativos indígenas y los esclavos africanos, dio a luz a una nación mestiza y, al mismo tiempo, marcado por una amplia desigualdad social y económica que asume perceptibles rasgos raciales. El sistema de clasificación de raza / color que se desarrolló en Brasil está íntimamente relacionado al proceso colonial. En los días actuales, se puede decir que hay dos grandes sistemas de clasificación étnico-raciales en el país: el oficial y el de uso cotidiano. El oficial está asentado en cinco categorías, cuatro referentes al color (blanco, negro, "pardo" y amarillo) y una referente a la etnia (indígena). El sistema de uso cotidiano, más flexible que el sistema oficial, varía según el tipo de interacción interpersonal. Los sistemas de clasificación racial, sin embargo, están asentados en las características físicas de los sujetos (con excepción de la categoría oficial "indígena"), teniendo el color de la piel como elemento más importante en el proceso de clasificación. Sin embargo, en los últimos 20 años, la lenta y silenciosa ascensión socioeconómica de parte de la población afrobrasileña, el proceso de discusión de las desigualdades socio-raciales, la emergencia de diferentes políticas de lucha contra la desigualdad social y la implantación de políticas de reparación enfocadas en

\footnotetext{
${ }^{1}$ Artigo apresentado no Simpósio Temático 12 - Relações Étnico-Raciais na América Latina: debates interseccionais na diáspora durante o II Seminário Latino-Americano de Estudos em Cultura - SEMLACult em Foz do Iguaçu/PR, Brasil, 2018.

${ }^{2}$ Doutor em Ciências Sociais; Universidade do Estado do Rio de Janeiro - UERJ; Rio de Janeiro, Rio de Janeiro, Brasil; guilherme.souza@uerj.br guilherme.nogueira.souza@hotmail.com
} 
la población afrobrasileña ha generado discusiones entre investigadores, gestores y activistas de movimientos sociales acerca de las categorías de clasificación y sus usos. Es en este contexto que el presente artículo desea examinar el sistema de clasificación racial, su estructuración, transformaciones y usos cotidianos, enfocándose en la población afrobrasileña.

Palabras claves: la desigualdad; identidades sociales; discriminación racial; relaciones raciales; sistema de clasificación.

\begin{abstract}
Brazil is the country with the largest afro-descendant population in Latin America. The Portuguese colonization process introduced the compulsory labor of natives of the most different African social groups and privileging the settlement and control of the territory through sexual intercourse with indigenous natives and slaves, gave rise to a mixed and at the same time marked by a broad social and economic inequality that assumes perceptible racial traits. The system of classification of race / color that has developed in Brazil is closely related to the colonial process. Nowadays, it can be said that there are two great systems of ethnic-racial classification in the country: the official and the daily use. The official is seated in five categories, four referring to the color (white, black, brown and yellow) and one referring to the ethnic (indigenous). The system of daily use, more flexible than the official system, varies according to the type of interpersonal interaction. Both racial classification systems, however, are based on the physical characteristics of the subjects (except for the official "indigenous" category), with skin color as a fundamental element in the classification process. However, in the last 20 years, the slow and silent socioeconomic rise of the Brazilian black population, the process of discussing socio-racial inequalities, the emergence of different policies to combat social inequality, and the implementation of compensatory policies focused on the population has generated wide public debates among researchers, managers and activists of social movements regarding classification categories and their uses. It is in this context that the present article discusses the system of racial classification, its structure, transformations and everyday uses, focusing on the Brazilian black population.
\end{abstract}

Keywords: inequality; social identities; racism; race relations; classification system.

\title{
1. Introdução
}

O Brasil é o país com a maior população afrodescendente de toda América Latina. O processo de colonização portuguesa, ao introduzir o trabalho compulsório de nativos dos mais diferentes grupos sociais africanos e privilegiar a povoação e controle do território via intercurso sexual com nativos indígenas e escravos, deu origem a uma nação miscigenada e, ao mesmo tempo, marcada por uma ampla desigualdade social e econômica que assume perceptíveis traços raciais.

O sistema de classificação de raça/ cor que se desenvolveu no Brasil está intimamente relacionado ao processo colonial. Nos dias atuais, pode-se dizer que há dois sistemas de classificação étnico-racial no país, ambos intimamente vinculados: o oficial e o de uso cotidiano. $\mathrm{O}$ oficial está assentado em cinco categorias, quatro referentes à cor (branco, preto, pardo e amarelo) e uma referente à etnia (indígena). O sistema de uso cotidiano, mais flexível que o sistema oficial, varia segundo o tipo de interação interpessoal, apresentando também um número bem maior de categorias. Ambos os sistemas de classificação racial, no entanto, estão assentados nas características físicas dos sujeitos (com exceção da categoria oficial "indígena"), tendo a cor da pele como elemento fundamental no processo de classificação. 
No entanto, nos últimos 20 anos, a lenta e silenciosa ascensão socioeconômica de parcelas da população negra brasileira, o processo de discussão das desigualdades sócio-raciais, a emergência de diferentes políticas de combate à desigualdade social e a implantação de políticas compensatórias focadas na população negra tem gerado amplos debates públicos entre pesquisadores, gestores e militantes de movimentos sociais a respeito das categorias de classificação e seus usos. É neste contexto que o presente artigo discute o sistema de classificação racial, sua estruturação, transformações e usos cotidianos, focando na população negra brasileira.

\section{O censo demográfico no Brasil}

Os primeiros levantamentos populacionais realizados no Brasil são datados ainda do Século XVIII. Por volta de 1750, por questões militares a Coroa Portuguesa decidiu realizar a contagem populacional de maneira direta. Até então, esta contagem era realizada de maneira fragmentada e indireta, através de registros de paróquias e levantamentos com pouco ou nenhum rigor metodológico, segundo relata o órgão oficial de estatística do governo brasileiro ${ }^{\mathrm{i}}$.

No entanto, segundo informações do mesmo órgão, demoraria quase 100 anos para que fosse feito o primeiro levantamento sistemático da população brasileira. As contagens populacionais realizadas entre 1765 e 1799 tinha o intuito de conhecer o tamanho da população livre e adulta, excluindo, portanto, toda a população negra escravizada, uma parcela importante do total da população. Ademais, estas contagens não possuíam o caráter "nacional", isso porque o Brasil, enquanto Estado soberano não existia; as contagens eram realizadas nas províncias da colônia e, estavam baseadas em registros paroquias.

Somente em 1850, quase 3 décadas após tornar-se um país independente, o único estado monárquico das Américas criou as condições necessárias para um levantamento censitário nacional, com aplicação de modernas técnicas demográficas para a época, sob a tutela e às dispensas do Governo. Entretanto, o referido censo só foi realizado 20 anos depois, em 1870, efeito da profunda reação popular aos projetos de lei da Monarquia.

A reação popular ao Decreto n. 797 de junho de 1851, apelidada de "lei do cativeiro" pelos cidadãos, deve-se ao receio dos camponeses livres e pobres da região nordeste no Brasil de que este processo de contagem tivesse como efeito a escravização dos mesmos. O referido decreto, oficialmente intitulado de Registro dos Nascimento e Óbitos, e seu anexo, a Lei do Censo, foram publicados no mesmo período em que o Legislativo aprovara a chamada Lei Eusébio de Queiros (1850), conjunto de artigos que, frente à pressão da Coroa Britânica, 
proibiam a entrada de escravos nos portos brasileiros. Apesar da conhecida ineficácia desta legislação, no momento de sua publicação, coincidindo com a publicação da Lei do Censo, moradores livres e pobres da região nordeste do Brasil, especialmente na antiga Província de Pernambuco - local de grandes movimentos sociais e políticos no Brasil do século XIX entenderam o conjunto de leis como preparativos para a transformação do trabalhador pobre e livre em escravo, visto a expectativa de que a proibição de entrada de mão de oba escrava negra gerasse ausência de braços para o trabalho na lavoura (PALACIOS, 2006).

O levante dos camponeses livres e pobres, muitos ex-escravos, - conhecido como "Guerra dos Marimbondos ${ }^{\mathrm{ii}}$ ", se espalhou por diferentes regiões do nordeste do país que, neste período, enfrentava um forte processo de empobrecimento de sua população. $\mathrm{O}$ receio de que a contagem populacional tivesse o efeito de tornar escravos homens até então livres se espalhou por diferentes províncias, o que inviabilizou a realização do censo. Apenas em 1870, quase no final do período monárquico da história brasileira, e como parte dos dilemas que o anunciado fim da escravidão negra produzia nos círculos da elite, foi finalmente organizado o primeiro censo nacional.

O episódio do nascimento do censo brasileiro já aponta para um signo que acompanharia este importante instrumento de análise e formulação de políticas públicas. Assim como no início, apesar de consolidado ao longo das décadas, o censo demográfico nunca deixou de ser alvo de disputas sociais e políticas. Assim como, o censo nunca deixou de se relacionar, mesmo que indiretamente, com as tensões para as quais apontavam o contexto social.

\subsection{Cor/ "raça" no censo brasileiro}

Ao longo dos anos, muitos estudos têm sido feitos a respeito dos sistemas de classificação segundo cor ou "raça" no Brasil (NOGUEIRA, 1985; FRY, 2005; RAMOS, 1995). O que se tem apontado em vários deles é a existência de um complexo e multivariado sistema de classificação composto por um conjunto variado de fatores que, em combinação, enquadram os sujeitos nas categorias deste sistema. Atributos físicos - como cor da pele ou textura do cabelo, por exemplo -, inserção de classe, escolaridade, status profissional, grau de proximidade, gênero e região são algumas das variáveis acionadas no processo de auto e alterclassificação segundo a cor ou "raça".

Um elemento importante neste processo são as categorias oficiais de classificação, aquelas usadas pelo IBGE. Os resultados destas pesquisas são fundamentais para as políticas públicas e a produção científica nacional. Entretanto, também estas categorias apresentam 
limitações e são alvo de crítica tanto de especialistas quanto do público em geral. Segundo o modelo atual, nascido no Censo de 1991, a população nacional pode ser classificada, segundo o pertencimento étnico-racial, como branca, preta, parda, amarela ou indígena.

“Até o século XIX, a informação relevante era a classificação da população em termos de sua condição civil, entre "livres" e escravos, e os recenseamentos de 1872 e 1890 já introduziam as questões de raça ou cor. Ao longo do século XX, é provável que as ideias racistas e as preocupações então existentes com o "melhoramento da raça" brasileira tenham influído na reintrodução do item de raça no recenseamento de 1940, da mesma maneira com que a noção de que no Brasil "não existe problema de raça" parece ter levado à exclusão do tema no censo de 1970." (SCHWARTZMAN, 1999, p. 2)

No Censo de 1940, apenas três categorias estavam disponíveis no sistema de classificação oficial de cor: "preta", "branca" e "amarela". Todas as categorias fora dessas três seriam enquadradas na categoria intermediária abrangente "parda". Portanto, "mulatos", "morenos", "caboclos", "cafusos", "índios" e toda uma ampla gama de categorias utilizadas para a classificação social e que fugiam dos extremos do gradiente de cor entre o "branco" e o "preto" ficaram ausentes da classificação oficial e foram enquadradas na categoria intermediária na sua maioria.

Diferentemente do Censo anterior, no ano de 1950, o formulário não previa as três categorias, abrindo caminho para a autoclassificação. No entanto, quando da liberação dos resultados, operou-se o mesmo procedimento de agrupar as categorias excedentes dentro do termo "pardo". Devido à conjuntura política, o Censo de 1960 não teve seus resultados divulgados e o Censo de 1970 não incluía o item "cor" dentre as suas perguntas tendo em vista que a "questão racial” não era um problema nacional (GUIMARÃES, 2001). O cenário político, portanto, é peça chave para compreender a inserção da "questão racial" e a sua operacionalização e conversão através da categoria “cor".

No Censo de 1980 a questão é reintroduzida com o mesmo conjunto de categorias da década de 50: "preta", "branca", "amarela" e "parda”. No Censo de 1991, acrescenta-se a estas categorias o termo "indígena" como forma de pensar a questão étnica indígena, retirando, portanto, este grupo social da classificação "pardo" e dando mais claramente o contorno étnico da classificação de "raça" ou cor. Esta estrutura se manteve no Censo de 2000 e, possivelmente, não sofrerá alteração para o Censo de 2010.

Independentemente de qual tenham sido as motivações de introdução do recorte étnicoracial nas pesquisas oficiais, fato é que hoje esses dados são fundamentais para pensar os processos de construção e reprodução de desigualdades na estrutura social e os mecanismos de 
acesso à estrutura pública em suas mais diversas esferas. Entretanto, apesar de sua funcionalidade, há um grande número de críticos a forma como as categorias de classificação étnico-racial estão dispostas, como argumenta Schwartzman (1999). A este respeito, cabe ressaltar que, em 2008, visando ampliar a discussão sobre as categorias de classificação de cor ou "raça" no Brasil, seguindo orientações da Conferência de Durban - 2001 - o IBGE organizou e implementou o projeto "Pesquisa das Características Étnico-Raciais da População/PCERP”:

Este projeto busca levantar subsídios para aprimorar o atual sistema de classificação de COR/RAÇA utilizado nas pesquisas do IBGE. A pesquisa foi realizada entre julho e setembro de 2008, com uma amostra de 25.000 domicílios em 5 estados da federação (AM, PB, SP, MT, RS) e DF. Partindo de uma introdução que faz um breve histórico dos levantamentos já realizados sobre este quesito na Instituição, pretendese discutir as possibilidades e os limites desse tipo de investigação temática em pesquisas estatísticas de cunho nacionaliii.

Os dados da PCERP, apesar de divulgados, ainda carecem de uma ampla análise por parte da comunidade científica brasileira. O debate sobre alterações nas categorias de classificação nos levantamentos oficiais precisa ser realizado com cuidado demasiado para que não ser perca a continuidade histórica dos dados.

Na perspectiva de problematizar a maneira como os dados sobre cor e etnia são produzidos, Wood \& Carvalho (1994), ao discutirem a complexa relação entre classificação oficial e a percepção subjetiva quanto à cor apontam para as dificuldades de processar essas categorias e demonstra o quanto que ao longo dos anos houve um processo de reclassificação segundo a cor. Através de um conjunto de instrumentos estatísticos, demonstram que, ao longo dos anos o contingente populacional que se enquadrava em cada uma das categorias oficiais se alterou de maneira significativa, sendo esse processo, possivelmente, indicativo de mudanças na estrutura social brasileira e também, mais recentemente, no âmbito das representações e da valoração dos termos classificatórios.

Baseados na perspectiva sociológica de que, tradicionalmente, a ascensão social possibilita uma reclassificação para as populações que se encontram mais próximas ao extremo claro do gradiente de cor brasileiro - tanto na autoclassificação quanto, e especialmente, na alterclassificação -, os autores se propõem a pesquisar se, no período de grande crescimento econômico, entre os anos 50 e 80, que afetou desigualmente os grupos segundo a cor, mas que afetou a todos os grupos de uma maneira ou de outra, houve um processo massivo de reclassificação, qual teria sido o sentido dessa reclassificação e os grupos de cor mais afetados. Contrariando as expectativas iniciais do modelo estatístico, concluem que o número de brasileiros autodeclarados de cor "branca" reduziu entre os anos de 50 e 80; por outro lado, a 
contingente de "pardos" aumentou e o de "pretos" também declinou de maneira significativa. A respeito do declínio de autodeclarados "brancos", comentam:

\begin{abstract}
Podemos apenas especular sobre as possíveis razões destes achados. Por exemplo, se houve um declínio do estigma associado ao ser pardo desde 1950, esta mudança tornaria mais fácil para as pessoas se classificarem como pardas em 1980, em comparação com o que ocorrera 30 anos antes, quando eram presumivelmente compelidas a se classificarem como brancas. Similarmente, pode ter havido um forte descenso, em termos de mobilidade, de pessoas que se autodefiniram como sendo brancas e que, pelo fato de ocuparem uma posição social inferior em 1980, se reclassificaram como pardas." (WOOD e CARVALHO, 1994, p. 12)
\end{abstract}

Entretanto, apesar dos dados contrariarem a expectativas do modelo estatístico, os autores dão indícios claros de que as categorias estatísticas apresentam um elevado grau de variação no tempo e também de acordo com o tipo de pergunta feita. Wood \& Carvalho argumentam que, dependendo da estrutura da pergunta - se pré-codificada nas categorias "preta", "branca" ou "parda"; ou não - a distribuição populacional varia. Isto ocorre, prosseguem eles, devido ao fato de que na classificação aberta o conjunto de categorias é muito maior que as usadas na classificação oficial.

Na PNAD ${ }^{\text {iv }}$ de 1976, no seu suplemento especial sobre cor/“raça", foram catalogados aproximadamente 200 termos para classificação de cor. Entretanto, 93,6\% dos indivíduos respondentes da pesquisa se concentram na articulação dos termos: "branca", "clara", "morenaclara", "morena", "parda" e "preta", dando uma estrutura de gradiente de cor. Chama a atenção o fato de não aparecem, de maneira significativa, as categorias "negra" e "mulata" (Idem).

Em estudo similar realizado para os Censos de 1980 e 1991, Carvalho, Wood \& Andrade (2003), apesar de uma alteração metodológica importante, obtêm o mesmo resultado a favor de um maior fluxo líquido de população em direção à categoria "parda". No entanto, demonstra que a categoria "branca" apresenta maior constância tanto no tempo quanto de acordo com o modelo de questionário aplicado. E, neste sentido, a fronteira entre as categorias "parda" e "preta" seria bem menos definida que a fronteira entre "branca" e "parda".

Apesar dos autores não explorarem esta maior estabilidade do contingente populacional autodeclarado de cor "branca", é possível indagar em que medida esta maior estabilidade não está intimamente associada às hierarquizações operacionalizadas na lógica do gradiente de cor. Por esta lógica, o polo negativo, menos valorizado, é exatamente aquele no qual estão as pessoas mais escuras - e não somente no sentido de tom da pele, mas no sentido de "marca" como um todo, incluindo situação de renda, status, escolaridade, atributos físicos etc. Portanto, seria no entorno deste polo que as gradações hierárquicas em consonância com a lógica de "marca" 
tornariam a opção pelas categorias classificatórias mais fluídas numa tentativa de negociação com o estigma e com as formas de subalternização fundamentadas na cor. O que não exclui que o fato de que:

A razão fundamental desse viés parece residir na natureza social do cálculo da identidade racial brasileira. As evidências aqui coletadas apoiam a ideia de que, no Brasil, não só o dinheiro embranquece como, inversamente, a pobreza também escurece.” (SILVA, 1999, pp 123-124 In HASENBALG ET AL., 1999)

Nesse sentido de dinamismo e de diferentes graus de constância e estabilidade das categorias de "cor" também aponto o trabalho de Maio ET AL. (2005). Este artigo, baseado no Estudo Pró-Saúde, se propõe explicitamente a verificar, tendo em vista o crescimento das demandas e pesquisas na área de saúde por perfil "racial", como operam as categorias de classificação "racial" e qual resultado se obtêm quando os mecanismos de coleta variam. O "survey", aplicado entre os funcionários de uma universidade pública do Rio de Janeiro, continha duas maneiras distintas de perguntar a cor do entrevistado - uma aberta e outra com categorias fechadas, como as do IBGE. Ao contrário do primeiro trabalho de Carvalho, no qual a categoria "negro" não apareceu de maneira significativa entre as respostas abertas, nesta pesquisa o termo aparece e de maneira significativa. Comparando as duas pesquisas é necessário ressaltar o fato da pesquisa de Maio ter sido realizada, no Rio de Janeiro, num ambiente universitário - apesar de estar focado em pessoal técnico-administrativo - uma década depois do trabalho de Carvalho. Ademais, o trabalho deste último foi baseado em dados nacionais obtidos no suplemento especial da PNAD de 1976. Estas diferenças são importantes de serem marcadas tendo em vista que o uso das categorias de classificação de cor possui uma marca de regionalidade, temporalidade e geração que são importantes neste processo.

Maio também conclui pela maior estabilidade do uso do termo "branca" entre a pergunta fechada e aberta, tanto entre homens como entre mulheres. Entretanto, o que chama atenção neste trabalho, é a relação que se estabelece entre as categorias "negra", "preta" e "parda". A este respeito os autores afirmam que:

Cerca de $24 \%$ daqueles se identificaram como 'pretos' e $31 \%$ daqueles autoclassificados como "negros" escolheram a cor/raça parda entre as categorias fechadas. Em relação aos participantes que se identificaram como morenos ou mestiços (pergunta aberta), $75 \%$ e $71 \%$, respectivamente, classificaram-se como pardos. Entre os mulatos, $85 \%$ incluíram-se nessa categoria. Cabe salientar que nestes subgrupos intermediários, $23 \%$ dos morenos e $25 \%$ dos mestiços classificaramse como brancos, e apenas $0,5 \%$ dos mulatos optaram por esta categoria na pergunta fechada (MAIO ET AL 2005, p. 4). 
Os resultados da pesquisa de Maio demonstram a operação circunstancial das categorias classificatórias e como estas categorias convertem-se umas nas outras de acordo com a estrutura da pergunta. Esse processo de reclassificação não é aleatório, ele é operacionalizado pela lógica do gradiente de cor sob a égide da "marca" de acordo com a capacidade do indivíduo de negociar o conteúdo simbólico de cada termo no processo de interação. E, nesse sentido, alguns termos apresentam maior nível de ambiguidade, como é o caso do termo "moreno" (SILVA, 1999).

A discussão sobre o uso das categorias censitárias e sua variabilidade é uma forma de apreender as maneiras como os termos são operacionalizados no processo de identificação de cor ou "raça". Existem, por certo, outras estratégias, mas esta pareceu ser a mais adequada como forma de apresentar a maneira como pessoas autodeclaradas "negras" operam com a classificação e as variações possíveis. Pelo dito acima e pela reflexão a partir de trabalhos de autores variados, com focos variados, pode se indagar em que medida os processos de alteração no sistema de classificação estejam caminhando para um suposto binarismo; ou então, em que medida as alterações nesse processo não estejam operando com uma lógica fundamental do sistema de classificação assentado na "marca" e que, portanto, seria menos uma ruptura e mais uma realocação interna ao próprio sistema de classificação.

\section{O termo "negro" e seus usos relativos}

A apresentação de diferentes usos dos termos classificatórios de cor ou raça pode, num primeiro momento, parecer contraditória com o uso mais ou menos generalizado do termo "negro" por parte dos entrevistados desta pesquisa. O que se pretende neste momento é discutir quais são os sentidos do uso deste termo e, em que medida, este uso é uma forma de ruptura com o sistema classificatório assentado na marca ou não, dentro dos limites de um trabalho qualitativo.

Quando Sheriff (2001) elabora seu estudo sobre categorias "raciais" no Morro do Sangue Bom, percebe de maneira bastante contundente como o uso dos termos de classificação é marcado, não pela inconstância, mas pela multiplicidade circunstancial de seus usos. A autora demonstra como os termos "preto", "pardo", "negro" e outros são acionados de maneiras diversas tendo em vista os interlocutores e o universo que envolve a interação; os termos são acionados sempre em referência aos demais envolvidos em cena e ao cenário preponderante da interação. Assim sendo, as categorias raciais apresentam-se como um roteiro no qual a linguagem varia com as posições. Em certa medida, o que a antropóloga percebe, no nível das 
interações interpessoais num espaço de classe supostamente homogêneo, é aquilo que os estudos apresentados anteriormente constataram com uma metodologia quantitativa. Neste sentido, a pesquisa de Sheriff lança luz sobre o processo de interação em uma região específica, mas que, por certo, não se reduz a dinâmica daquela localidade.

Se, por certo, tendo em vista os estudos quantitativos, a determinação circunstancial do uso das categorias de cor ou raça não é uma exclusividade da região estudada, é possível se indagar como se dá o uso destas mesmas categorias quando se altera a classe em questão. E, neste sentido, os profissionais autodeclarados "negros" que compõem a fonte dos dados do presente trabalho são bastante eloquentes.

Sheriff demonstra como que para algumas pessoas o uso do termo "negro" assumia um caráter pejorativo e carregado de um sentido simbólico depreciativo e associado à violência. Diferentemente, os profissionais de classe média - cujo lugar na estrutura social é, supõe-se, significativamente distinto dos moradores de uma favela carioca - tomam esse termo como a expressão de seu lugar no mundo social; não somente no que se refere a uma inserção de classe que é diferenciada do lugar estrutural ocupado pela maioria da população "preta" e "parda" segundo categorias e dados oficiais - mas também pela excepcionalidade racial que a sua inserção profissional enquanto corpo "não-branco" em um espaço ou posição hierárquica dominado por pessoas reconhecidas socialmente como "brancas". Essa dupla diferenciação é a chave interpretativa a partir da qual se pode compreender como se dá o processo de ressignificação do termo "negro" e seu uso mais ou menos homogeneizado dentro de um recorte de escolaridade, atividade e renda.

No entanto, se os profissionais entrevistados operam com a categoria "negro" de modo diverso daquela com que opera a criança citada por Sheriff (2001, p. 223), os sentidos aplicados a esse termo precisam ser desvendados de modo a perceber em que medida ele se afasta ou se aproxima de outros usos. O trabalho da autora demonstra a centralidade da corporalidade na definição e uso dos diferentes termos. Está no corpo e nas características deste corpo a chave para o processo de classificação. E, neste sentido, a forma como os profissionais operam - e isso aparece até mesmo nas falas de militantes de movimentos sociais de caráter "racial" - com as categorias de classificação cor ou "raça" é semelhante à dos entrevistados de Sheriff. Em ambos os casos, não fica muito distante da lógica apresentada por Nogueira (1985) com o conceito de "preconceito de marca".

A lógica do "preconceito de marca" supõe a existência de um sistema classificatório multivariado no qual entra em operação traços físicos, grau de proximidade e caráter da relação social, status profissional e educacional, poder econômico e social, e, por fim, intencionalidade 
da interação. Esse conjunto de elementos é rapidamente acionado no processo de marcação simbólica da diferença. Nogueira não está focado na existência desse sistema e sim em uma forma particular de construir, reproduzir e manter desigualdades sociais de caráter "racial". Porém, daquilo que escreve sobre o município de Itapetininga e suas relações "raciais", é possível extrair a existência de um sistema eficiente de marcação da diferença e de desqualificação ou supervalorização das diferenças. Os profissionais de classe média que se autodeclaram "negros" são eficientes no processo de construção da imagem de si seguindo a lógica do uso do termo "negro" mas, ao mesmo tempo, operam também com a lógica do sistema de "marca", com a lógica da gradação de cor e das diferenças assentadas no corpo e não necessariamente em alguma ancestralidade. A este respeito, uma entrevistada (31 anos) formada em Turismo e que atua como guia de turismo internacional declara quando indagada como definia sua cor:

\footnotetext{
Pesquisador - Como você define sua cor?

Entrevistada - Preta, negra... Não me incomodo de ser chamada de preta, pretinha. Para mim nada disso é pejorativo, pejorativo é o que vem depois.

$\mathrm{P}$ - E como você define a cor dos seus pais?

E - A minha mãe tem essa cor de... É tão sarará que não tem nenhuma outra pessoa da cor dela. A minha mãe é mais branca que eu.

$\mathrm{P}$ - E como definiria a cor do seu pai?

E - Também é. Também. E o meu pai é meio etíope porque ele tem aquela cor negra e o cabelo liso, sabe? Um gato!
}

O pequeno fragmento acima revela algumas das operações possíveis com o uso do termo “negro". Durante toda a entrevista a construção narrativa sobre si e o seu lugar no mundo foi marcada pelo uso deste termo, mas sempre com um sentindo muito assentado nas características física, no corpo e a sua centralidade no processo de classificação racial, algo relativamente "tradicional” no processo de definição de pertencimento racial no país. É expressivo deste momento, apesar de se declarar filha de um casal de negros, o fato de não conseguir um termo comparativo para classificar a cor da mãe. A centralidade do corpo neste processo se tornou tão ampla que, num determinado momento, a entrevistada julgou necessário apresentar fotos de toda a família, o que inclui: marido, pais, tios, primos e primas. E no processo de apresentação familiar, os termos "moreno", "pardo", "branquinho", "clarinho" deram a tônica das narrativas.

A fala sobre as características paternas também seguem a mesma lógica da narrativa profundamente centrada no corpo concreto e nos seus traços fundamentais. Não basta afirmar que, para a entrevistada, seu pai é "negro"; é fundamental qualificar a aparência do pai no processo narrativo. Mais adiante, a mesma entrevistada falando a respeito de como supunha que seus pais se classificavam afirma: 
P - Você tem ideia de como os seus pais se definem atualmente, em relação à cor?

E - Quanto à cor? Minha mãe diz que é negra... Eu posso dizer que ela tem traços afrodescendente, mas não que ela é negra.

$\mathrm{P}$ - E o seu pai?

E - O meu pai diz que é moreno, só que ele tem aquele cabelo liso...Aí eu falo: ‘sai daí seu etíope, tu é o mais negro de todos! Tu é preto de preto. Sai daí negão!’[risos] Ai ele: 'eu sou moreno!' As outras gerações sofreram muito mais...antigamente era feio dizer que era preto. Imagina que absurdo ter...na certidão de nascimento...o meu pai... Eu sou filha do segundo casamento do meu pai. Os meus irmãos são bem mais velhos do que eu. Eu tenho trinta e um e o meu irmão deve estar com quarenta. A minha irmã cinquenta...Aí, eles dois são negros. Na certidão de nascimento deles está 'asterisco' ...No lugar da cor... Não, minto...a minha irmã que é da minha cor... a minha irmã é da minha cor e na certidão dela tem asterisco. Você já viu isso? Já ouviu falar nisso? Procura saber... Pessoas que tem cinquenta anos que sejam bem negras, pede a certidão de nascimento pra você ver. Aí, quando a pessoa é preta pra não dizer que é preta bota asterisco. E o meu irmão como ele é mais claro do que eu...o meu irmão é da cor do meu marido...tem escrito na certidão de nascimento dele pardo. Pardo pra mim é japonês, me desculpa.

Independentemente da veracidade a aplicação dos asteriscos no lugar da cor das crianças pretas no Brasil ao serem registradas em décadas passadas, é interessante ter registrado como se dá aplicação do termo "negro" e o quanto o seu uso está fundamentado no corpo. Cabe frisar que, do ponto de vista do pesquisador, a entrevistada tinha a possibilidade de ocupar uma posição bastante intermediária no gradiente de cor; possivelmente a autoclassificação como "morena" ou "parda" não geraria nenhum estranhamento nas redes socializadas com a lógica da "marca".

Outro entrevistado, advogado e estatístico (45 anos), atuando no serviço público federal em posição de destaque, quando indagado quanto a sua cor, responde: "P - Como é que você classifica a sua cor? E - Eu sou - eu me considero negro. P - Segundo o IBGE: preto, pardo ou branco? E - Pardo. Segundo o IBGE, é pardo.”

Mais uma vez os termos são intercambiáveis nas falas de autoclassificação. Ao contrário da entrevistada citada anteriormente, este homem fala pouco de questões associadas a pertencimento "racial". E sua percepção do sentido de ser "negro" está fortemente fincada na sua aparência, no seu corpo que o apresenta como homem "negro" em todos os espaços que atua. Quando indagado se havia algum sentido especial ou alguma definição do que seria ser um homem "negro", responde: "Sinceramente, eu só penso na cor da pele. Eu não consigo imaginar alguma diferença cultural ou alguma questão, algum outro traço de raça que caracterize uma pessoa ser branca, ou negra, ou amarela. Não consigo, eu só penso na cor da pele".

Ainda tentando saber como operava a lógica de classificação na narrativa deste entrevistado que, apesar de um passado sindicalista e militante de partido político, nunca se 
envolveu concretamente com nenhuma organização dos movimentos negros - mesmo conhecendo-as de perto, indaguei quanto à cor do seu filho, um adolescente, fruto do seu primeiro casamento:

\footnotetext{
P - Seu filho também é negro?

E - Não, para a sociedade ele não seria considerado negro. Ele é bem mais claro do que nós e não tem traços...o nariz, a boca. Ele puxou muito mais a mãe, que é branca. Apesar de ser nordestina, mas é muito branca. Então, ele, apesar de ser filho de um negro com uma branca, mas ele tem muito mais os traços...

$\mathrm{P}$ - Os traços da mãe?

E - Os traços, não é? Se alguém perguntar para ele, ou se alguém perguntar sobre ele, vão dizer que é branco.
}

Assim como na entrevista anteriormente citada, este entrevistado teria condições, caso quisesse, de se enquadrar em outro grupo de classificação pensando na lógica do gradiente de cor. Tanto é verdade que seus companheiros de trabalho, num contexto de uma piada contra "pretos", alegaram: "Não, mas você não é preto. Você é moreno".

A médica cardiologista (51 anos), autodeclarada "negra", sócia de uma grande empresa prestadora de serviços médicos na cidade do Rio de Janeiro, ao ser indagada sobre a cor da sua filha, declara: "P - E quanto a sua filha, você a considera "negra"? E - Ela é porque é minha filha, mas ela é bem clara, mesmo porque meu marido era branco."

Esta fala se torna importante - e até certo ponto destoante - exatamente porque a entrevistada não possui experiências em grupos de militantes ou movimentos sociais; em outras palavras, não foi socializada politicamente no interior de grupos militantes com uma proposta de definição de pertencimento "racial" enquanto fundamentado na ancestralidade como propõem alguns agentes e instituições políticas. Entretanto, sua fala é marcada por um princípio de ancestralidade que apenas cede lugar quando pensa na existência ou não de barreiras raciais para sua filha. Nesse sentido, exatamente porque a menina é "bem clara", a mãe não acredita que enfrentará barreiras raciais porque dificilmente será classificada como "negra" por qualquer pessoa. Assim sendo, a filha é "negra" e, ao mesmo tempo, não é; ela é negra do ponto de vista da mãe, mas, dificilmente, será classificada assim pelas demais pessoas com quem convive desde que classificados no interior da lógica do "gradiente de cor" e da "marca".

Outro entrevistado que também utiliza um critério de ancestralidade para se autoclassificar e classificar as filhas como negras é o engenheiro cartográfico de 50 anos. Para este, suas filhas são "negras" exatamente porque são filhas de um casal de "negros".

P - E em relação aos seus filhos? Você os classificaria, e eles se classificam, como negros? 
E - Sim, classifico como negros, as mães são negras. Uma militante, a outra não é. Elas se veem como negras, e meus filhos se veem como negros, são antenados na questão racial.

Neste caso, fica a dúvida se os filhos são "negros" exatamente porque são filhos dele, ou seja, a classificação expressaria um posicionamento político do militante histórico; ou se os filhos são "negros" porque possuem características físicas que assim possam ser classificadas tendo em vista que nascidos de um casal de negros. Será que se os filhos não tivessem traços "negros", eles seriam igualmente classificados como negros? Não existe a possibilidade de responder a esta pergunta posto que a situação nada mais é que especulação. No entanto, esses dois casos são emblemáticos exatamente porque fazem uma articulação entre uma classificação "racial" dominante e assentada nas características do corpo e certo "projeto" de política racial, ou melhor, um projeto político de classificação racial.

Cabe ressaltar que estes dois agentes entrevistados possuem relações bastante distintas com a esfera política, seja ela institucional, seja ela militante; enquanto a primeira nunca possui nenhum tipo de vínculo e se apresenta como cética das capacidades dos movimentos sociais ou da política institucional no processo de mudanças efetivas, o segundo possui filiação políticopartidária, tendo ocupado cargos de destaque no cenário político fluminense. Sobre este é necessário citar o fato de que sua ex-esposa foi uma das lideranças políticas mais importantes na cidade do Rio de Janeiro. E uma figura de destaque nas discussões sobre reserva de vagas nas universidades deste estado.

Em certa medida, os entrevistados acima citados são exemplos de uma postura recorrente no processo de autoclassificação destes profissionais negros quanto ao pertencimento "racial". Ao definir-se como "negros" não estão abrindo mão de outras categorias de classificação e não necessariamente estão supondo a construção de um sistema binário de classificação "racial” como existente no EUA.

Há uma recorrente e significativa centralidade do corpo neste processo de construção de pertencimento racial. E este dado precisa ser levado em consideração no processo de análise deste pertencimento. Ademais, a estratégia de indagar a respeito da classificação racial dos familiares demonstrou-se bastante produtiva ao revelar maiores detalhes de um projeto pessoal de autoclassificação e o seu limite ao classificar o outro, especialmente por ter com este outro uma relação de proximidade, não se tratando apenas de uma classificação formal. Para muitos - mais recorrente que o contrário - os traços físicos dos filhos são mais importantes que sua ascendência na definição do pertencimento racial destes. De igual modo, o pertencimento "racial" dos pais dos entrevistados dá bons indicativos da forma como a noção de "marca" atua, 
tendo em vista o fato de que o determinante para se definir como "negro", mesmo sendo filho de um casal misto, são os traços físicos, fenotípicos.

\section{Considerações finais}

O círculo social no qual estão inseridos os entrevistados é composto majoritariamente por homens e mulheres brancos. A classe social parece ser mais central do que outras formas de pertencimento no que se refere à construção de redes sociais. E, exatamente por isso, ao se referirem às redes de sociabilidade, é sempre presente a informação de que, ao longo de toda a vida, nunca tiveram dificuldades em estabelecer contatos fraternos e profissionais com pessoas brancas. Não aparecem em nenhuma das entrevistas, narrativas assentadas na exclusão social segundo a cor de pessoas brancas. Antes, a recusa a uma sociedade segregada aparece como elemento central da crítica aos padrões de desigualdade no Brasil.

A categoria "pardo" aparece em várias entrevistas. Ora como classificação, ora como objeto de críticas. E, em alguns casos, a junção dos dois. A crítica mais frequente a esta categoria é a dificuldade de definir o seu conteúdo real. Alguns alegam que "pardo é papel”, "pardo é japonês" ou ainda, "não sei o que é ser pardo". Todas as categorias de classificação são construtos, são produtos do processo social de construção da realidade. Entretanto, na fala dos interlocutores, é como se houvesse categorias mais reais que outras. E "pardo", por certo, não está dentre as categorias com maior uso e legitimidade social, ao menos neste grupo social.

Outras categorias como "moreno" e "mulato" aparecem com um uso mais pontual. E mais do que isso, aparece mantendo uma dinâmica tradicional, uma concepção de mulato como resultado do intercâmbio sexual entre brancos e pretos. Mulato aparece mais como uma categoria descritiva do que como uma categoria identitária. Interlocutores com pais de cores distintas se apresentaram como negros e, ao mesmo tempo, se referiram a outros, com o mesmo arranjo familiar, como mulatos. Pais descrevem os próprios filhos como mulatos e, ao mesmo tempo, os definem como negros.

Em alguns casos, a categoria "negro" parece ser equiparada a categoria "preto", como forma descritiva, e não necessariamente identitária. Nesses casos, parece que o termo "preto" e o termo "negro" se tornam sinônimos, forças descritivas negociando com a gramática racial brasileira. Quando o termo negro perde o caráter identitário, para se tornar apenas uma categoria descritiva, deixa de ser englobante das categorias "mulato", "mestiço" ou "pardo" e passa a ser uma categoria concorrente. 
Os usos das categorias classificatórias pelos interlocutores é expressão de parte de uma tradicional gramática classificatória cujos termos são intercambiáveis segundo as circunstâncias. Não há gramática que não sofra alteração com o uso, nem a gramática racial. É possível pensar que, no que se refere às categorias classificatórias e a construção das identidades sociais, em meio a um conjunto de alterações, com a emergência de novas categorias e a aposentadoria de outras. Apesar de parecer ser uma versão da mesma gramática, os homens e mulheres de classe média parecem ter um repertório bem mais limitado que o conjunto da população. Talvez efeito da região - Rio de Janeiro -, talvez efeito de uma escolarização/ socialização diferenciada, talvez como consequência de um projeto político-identitário particular, ou mesmo todas essas possibilidades congregadas, há a emergência de uma categoria que não era representativa no passado e torna-se agora, com forte caráter identitário.

\section{Referências}

AZEVEDO, T de. As elites de cor: um estudo sobre ascensão social. São Paulo: Nacional, 1955.

CARVALHO, J.A.M. de; WOOD, C.H. \& ANDRADE, F.C.D. Notas acerca das categorias de cor dos censos e sobre a classificação subjetiva de cor no Brasil: 1980/1990. Revista Brasileira de Estudos de População, v. 20, n.1, jan./jun. 2003

FARIAS, Patrícia Silveira. Pegando uma cor na praia. Rio de Janeiro: Secretaria Municipal das Culturas, Departamento Geral de Documentação e Informação Cultural, Divisão de Editoração, 2003.

FERNANDES, Florestan. A integração do negro na sociedade de classes. São Paulo: Dominus Editora/ Editora da Universidade de São Paulo, 1965.

FIGUEIREDO, Ângela. Fora do jogo: a experiência dos negros na classe média brasileira. Caderno Pagu. $\mathrm{n}^{\circ}$ 23. Campinas: 2004.

Novas elites de cor: estudo sobre os profissionais liberais negros de Salvador.

UCAM. Rio de Janeiro: 2002.

Maldita ou bendita classe média negra? Revista Interseções. Ano 6. $\mathrm{n}^{\circ} 1$. Rio de Janeiro: 2004

FRY, Peter. A persistência da raça: ensaios antropológicos sobre o Brasil e a África austral. Rio de Janeiro: Civilização brasileira, 2005.

GUERREIRO RAMOS, Alberto. Introdução crítica a sociologia brasileira. Rio de Janeiro: UFRJ, 1995.

GUIMARÃES, Antônio Sérgio Alfredo. A questão racial na política brasileira (os últimos quinze anos). Tempo Social; Ver. Sociol. USP, São Paulo, 13(2): 121-142, novembro de 2001.

HERINGER, Rosana. Desigualdades raciais no Brasil: síntese de indicadores e desafios no campo da política pública no Brasil. Rio de Janeiro: Cad. de Saúde Pública, nº 18, 2002. HASENBALG, Carlos. Discriminação e desigualdades raciais no Brasil. Belo Horizonte: UFMG, 2005

SILVA, Nelson do Valle e LIMA, Márcia. Cor e estratificação social. Rio de Janeiro: Contra Capa Livraria, 1999 
LIMA, Márcia \& Abdal, Alexandre. Educação e trabalho: a inserção dos ocupados de nível superior no mercado formal. Revista Sociologias, Porto Alegre, ano 9, nº 17, jan/jun. 2007, p. $216-238$.

SHERIFF, Robin E. Como os senhores chamavam os escravos: discursos sobre cor, raça e racismo num morro carioca. In MAGGIE, Yvonne e REZENDE, Claudia Barcellos (org.). Raça como retórica: a construção da diferença. Rio de Janeiro: Civilização Brasileira, 2002. MAIO, Marcos Chor; MONTEIRO, Simone; CHOR, Dóra; FAERSTEIN, Eduardo e LOPES, Claudia S. Cor e raça no Estudo Pró-Saúde: resultado comparativo de dois métodos de autoclassificação no Rio de Janeiro, Brasil. Cadernos Saúde Pública, Rio de Janeiro, 21(1): 171- 180, jan-fev., 2005.

NOGUEIRA, Oracy. Tanto preto quanto branco: estudo de relações raciais. São Paulo: T.A. Queiroz Editor, 1985.

PALACIOS, Guillermo. Revoltas camponesas no Brasil escravista: a 'Guerra dos Maribondos' (Pernambuco, 1851-1852). Revista Almanack Braziliense, nº3, maio, 2006. PINTO, L.A. Costa. O Negro no Rio de Janeiro: relações de raça numa sociedade em mudança. Rio de Janeiro: Editora UFRJ, 1998.

SANSONE, Lívio. Negritude sem etnicidade: o local e o global nas relações raciais e na produção da cultura negra do Brasil. EDUFBA/ Pallas. Salvador: 2004.

SOARES, Reinaldo da Silva. Negros de classe média em São Paulo: estilo de vida e identidade negra. Tese de Doutorado: FFLCH\USP. São Paulo: 2004.

O cotidiano de uma escola de samba paulista: o caso do Vai-Vai. Dissertação de Mestrado: FFLCH\ USP. São Paulo: 1999.

SOUZA, Guilherme Nogueira de. Os negros ascendentes na região metropolitana do Rio de Janeiro: trajetórias e perspectivas. Tese de Doutorado: PPCIS/UERJ. Rio de Janeiro, 2012.

Os negros de camadas médias no Rio de Janeiro: um estudo sobre identidades

sociais. Dissertação de Mestrado: PPCIS/UERJ. Rio de Janeiro, 2008.

SCHWARTZMAN, Simon. Fora de foco: diversidade e identidades étnicas no Brasil. Novos Estudos CEBRAP, 55, novembro 1999, pp. 83-96

TEIXEIRA, Moema de Poli. Negros na universidade. Rio de Janeiro: Pallas, 2003

VELHO, Gilberto. Individualismo e cultura. Rio de Janeiro: Zahar, 2004

Subjetividade e sociedade: uma experiência de geração. Rio de Janeiro: Zahar, 1987.

WOOD, C.H. e CARVALHO, J.A.M, de. Categorias do censo e classificação subjetiva de cor no Brasil. Revista brasileira de estudos de população, v.11, n.1, 1994.

\footnotetext{
${ }^{\text {i } I n s t i t u t o ~ B r a s i l e i r o ~ d e ~ G e o g r a f i a ~ E s t a t i ́ s t i c a ~-~ I B G E . ~ F o n t e: ~ h t t p: / / w w w . i b g e . g o v . b r / c e n s o / c e n s o b r a s i l . s h t m, ~}$ consultado em 10/10/2012.

ii Nome comum a várias espécies de vespas dotadas de aguilhão inoculador de veneno (Dicionário Michaelis versão eletrônica).

iii Fonte: http://www.ibge.gov.br/home/estatistica/populacao/caracteristicas_raciais/default_raciais.shtm, consultado em 25/04/2010.

iv Pesquisa Nacional por Amostra de Domicílios é realizada pelo Instituto Brasileiro de Geografia e Estatística, consiste num levantamento domiciliar das condições socioeconômicas das diferentes regiões do país. Iniciada em 1967, a pesquisa possui duas propostas fundamentais: suprir a falta de informações sobre a população brasileira durante o período intercensitário; estudar temas insuficientemente investigados ou não contemplados nos censos demográficos decenais realizados por aquela instituição. Maiores detalhes: http://portal.mec.gov.br/index.php?option=com_content\&view=article\&id=12521:inf
} 